\title{
A study of turbulent heat transfer in convergent-divergent shaped microchannel with ribs and cavities using CFD
}

\author{
P. Srivastava ${ }^{1,2}$ and A. Dewan ${ }^{2 *}$ \\ ${ }^{1}$ Instruments Research and Development Establishment, Defence Research and Development Organisation Dehradun - 248008, \\ Uttarakhand, India \\ 2 Department of Applied Mechanics, Indian Institute of Technology Delhi, Hauz Khas, New Delhi - 110016, India. Phone: +911126591217
}

ABSTRACT - This paper presents the effects of microchannel shape with ribs and cavities on turbulent heat transfer. Three-dimensional conjugate heat transfer using the SST $k$ - $\omega$ turbulence model has been investigated for four different microchannels, namely, rectangular, rectangular with ribs and cavities, convergent-divergent $(C D)$ and convergent-divergent with ribs and cavities (CD-RC). The flow field, pressure and temperature distributions and friction factor are analyzed, and thermal resistance and average Nusselt number are compared. The thermal performance of the CD-RC microchannel is found to be better than that of other microchannels considered in terms of an average Nusselt number increased from $16 \%$ to $40 \%$. Heat transfer increases due to a strong fluid mixing and periodic interruption of boundary-layer. It is observed that with an increase in Reynolds number $(R e)$, the thermal resitance drops rapidly. The thermal resistance of the $\mathrm{CD}-\mathrm{RC}$ microchannel is decreased by $30 \%$ than that of the rectangular microchannel for $R e$ ranging from 2500 to 7000 . However, such design of microchannel loses its heat transfer effectiveness due to a high pumping power at high values of $R e$.

\section{ARTICLE HISTORY}

Revised: 22 ${ }^{\text {nd }}$ Oct 2019

Accepted: $5^{\text {th }}$ Nov 2019

\section{KEYWORDS}

Heat transfer enhancement; turbulent heat transfer; thermal resistance; convergent-divergent microchannel; ribs and cavities.

\section{INTRODUCTION}

An effective cooling mechanism is one of the major concerns in electronic industry to remove high heat flux from electronic components substrate in order to improve the performance of such systems. Microchannel liquid cooling is one of the potential candidates for this purpose. It has a large surface area to volume ratio for heat transfer. However, it requires a high pressure head to flow the working fluid in channel. Tuckerman and Pease [1] used microchannels and showed high heat removal of approximate $790 \mathrm{~W} / \mathrm{cm}^{2}$. They analysed the thermal performance and flow characteristics using various substrate materials, different aspect ratios and working fluids. The effect of microchannel shape and significance of ribs and cavities on heat transfer enhancement has been carried out [2]. A comprehensive review on various methods of heat transfer enhancement in microchannel has been carried out by Dewan and Srivastava [3].

Dewan and Kamal [4] investigated the effect of aspect ratio on heat transfer characteristics in an interrupted microchannel. Xie et al. [5] investigated the effects of different geometrical parameters of channel, such as, overall thickness, substrate thickness, and flow rate on heat transfer characteristics using the standard $k-\varepsilon$ model. They showed that thermal performance could be improved by using a narrow and deep channel with thin bottom surface thickness with a high but acceptable pumping power. Srivastava et al. [6] investigated the effects of ribs and cavities on convergent-divergent shaped microchannel in laminar flow condition and showed that a uniform and lower substrate temperature could be achieved with a lower pressure drop penalty. Duryodhan et al. [7] performed experimental investigation on the shape of a microchannel and concluded that a converging microchannel had a better performance compared to a diverging one under similar conditions. The effects of bifurcation plate were investigated by Srivastava and Dewan [8] as a heat transfer enhancement method with a lower and uniform bottom surface temperature.

Nanofluids have also been considered for thermal performance enhancement in microchannels. A nanofluid is prepared by dispersing particles of metal or metal oxides with sizes of $100 \mathrm{~nm}$ or less, in a base liquid, such as, water to achieve large values of the heat transfer coefficient. Hussein et al. [9] presented a review paper on heat transfer enhancement with nanofluids and concluded that the concentration of nanofluid, the operating temperature, the particle size and shape, and the material of the nanoparticle had significant influence on the heat transfer coefficient. Sangmesh et al. [10] investigated the convective heat transfer for MWCNT based nanofluids flowing in fluid pockets within the base of the heat sink and heat transfer effectiveness was measured in terms of a reduced junction temperature of the LEDs. They observed a reduction in the thermal resistance by $15 \%$. Abidin et al. [11] reported an experimental study on forced convective heat transfer performance of the CNF-based nanofluid in a laminar flow through a mini heat transfer test rig and showed that the presence of nanoparticles increased the heat transfer coefficient.

Some researchers reported turbulent heat transfer characteristics in a microchannel. Menni et al. [12] presented flow and heat transfer characteristics in rectangular cross section channels with various models of $S$-shaped baffles using air as the working fluid at Reynolds numbers ranging from 12000 to 32000. They observed that the channel containing the 
$S$-obstacles with a large $R e$ had higher heat transfer, friction loss, and thermal enhancement factor than the one with a smaller Re. Liu and Garimella [13] conducted a test on microchannel and observed a good agreement with correlations data and friction factor data for turbulent flow. They inserted dye in flow to observe the critical Reynolds number. Wang and Peng [14] carried out experiments on microchannels with rectangular cross-section and showed that the Dittus - Boelter correlation could be used for a fully developed turbulent heat transfer. They also concluded that heat transfer was strongly affected by flowing fluid flow rate and its temperature. Adams et al. [15] used the classical Gnielinski Nusselt number correlation to predict heat transfer characteristics for a turbulent flow and concluded that a threshold value for the hydraulic diameter could be used for the determination by the conventional correlations. Li and Olsen [16] carried out experiments using Microscopic Particle Image Velocimetry (micro-PIV) on square microchannels. They used fluorescent seed particles with water and found fully turbulent flow for $R e$ ranging from 2600 to 2900. They also reported detailed results on velocity fluctuations and Reynolds stresses using micro-PIV data. Oumer et al. [17] investigated the effects of the inlet temperature on heat transfer characteristics of supercritical fluids in minichannels and compared their results with the experimental results. Both the results showed that the wall temperature increased along the tube length due to a high convective heat transfer occurring at the entrance of the heated section of the pipe. Rahman [18] designed two different channel patterns ( $I$-channel and $U$-channel) to assess the effects of flow branching, channel length and fluid velocity. It was observed that heat transfer was enhanced by an interruption of the velocity boundary-layer due to the surface roughness of the etched channel structure. Al-Naema et al. [19] used serpentine rectangular microchannels with four different geometrical configurations and observed a good agreement between numerical predictions and experimental results. Adib et al. [20] presented three-dimensional flow pattern of blood through an $S$-shaped artery and it was shown that the flow at the entrance accelerated rapidly until arriving at certain nodes with the maximum velocity. This modeling of the geometrical $S$-shaped artery is suitable for understanding the pattern of blood flow under a constant normal blood pressure.

Interruption and mixing of main flow using microstructures, and change in geometrical configurations have also been used by many researchers to augment turbulent heat transfer. Cheng et al. [21] used four different tapered microchannels for Re ranging from 1300 - 3400. Their results showed that an early turbulence could be achieved at low values of $R e$ leading to a good heat transfer. Chan et al. [22] investigated the effects of Reynolds number on heat transfer enhancement in straight and serpentine channels of semi-circular cross-section with the hydraulic diameter 10 $\mu \mathrm{m}$ and showed that the heat transfer coefficient was enhanced in the region of serpentine bends due to an increase in dean vortices with $R e$. Wang et al. [23] used microchannel with pillar for Re range of 100 - 5600 and showed that a double value of heat transfer coefficient could be achieved using pillar in microchannel compared to that without a pillar. They also concluded that a triangular pillar performed the best among all geometries considered. Rezaie et al. [24] used semi-truncated and semi-attached ribs in rectangular microchannel and investigated the effect of forms and numbers of ribs on heat transfer characteristics. They concluded that flow turbulence could be increased and velocity distribution could be affected by the existence of ribs in flow direction leading to an increase in convection heat transfer. Sharma et al. [25] used truncated prismatic ribs to interrupt the flow field and showed the effect of rib configurations on flow pattern and heat transfer characteristics for Re ranging from 9400 - 58850. They observed an increase in Nusselt number of approximately $25 \%$ with $55 \%$ pressure drop penalty. Abdulrajjak et al. [26] investigated the effects of different angles of triangular ribs with $R e$ varying from 20000 to 60000 on heat transfer characteristics.

The above-mentioned literature review shows that the reported studies have focused on various heat transfer augmentation methods using pillars, ribs, cavities and changes in shapes of microchannel. The individual effects of shapes of microchannel and flow disruption techniques on thermal characteristics were analysed by many researchers. In the present paper, turbulent heat transfer characteristics are analysed in a convergent-divergent shaped microchannel, which creates sudden expansion and contraction of the flow area leading to a strong mixing of cold and hot fluids. Further the effects of ribs and cavities present in the fluid domain, which interrupt the boundary layers, on flow and heat transfer characteristics, are analysed. The present authors have earlier carried out an investigation on the effects of the channel shape with different flow disruption techniques for a laminar flow and have also studied combined effects of shape change and flow disruption [6]. A similar study for turbulent flow has not been reported, which motivated the present authors to carry out this study.

In the present paper combined effect of flow disruption using ribs and cavities with change in shape of microchannel using a CD shape has been investigated for $R e$ ranging from 2500 to 7000 . In the following sections the microchannel is first introduced followed by the mathematical description and performance comparison in terms of the average Nusselt number and thermal resistance.

\section{GEOMETRY AND MATHEMATICAL DESCRIPTION}

\section{Dimensional Details}

Convergent-divergent microchannels with the following four geometries were considered in the present study to investigate the effects of channel shape with ribs and cavities.

Case 1. Rectangular microchannel

Case 2. Rectangular microchannel with ribs and cavities

Case 3. Convergent-divergent microchannel

Case 4. Convergent-divergent microchannel with ribs and cavities 
A schematic of the convergent-divergent shaped microchannel with ribs and cavities along the flow direction is shown in Figure 1. In the present study, 10 microchannels were arranged in a substrate with the bottom size of $10 \mathrm{~mm} x$ $1 \mathrm{~mm}$ (length $\mathrm{x}$ width) and a depth of $0.9 \mathrm{~mm}$. The geometric parameters of each computational domain are given in Table 1.

Table 1. Dimensions of microchannel (all dimensions are in $\mathrm{mm}$ ) shown in Figure 1.

\begin{tabular}{ccccc}
\hline $\mathbf{L}$ & $\mathbf{H}$ & $\mathbf{W}$ & $\mathbf{H}_{\mathbf{f}}$ & $\mathbf{W}_{\mathbf{f}}$ \\
\hline 10.0 & 0.9 & 0.1 & 0.057 & 0.03 \\
\hline
\end{tabular}

Figure 2 shows detailed geometrical configuration of each microchannel that was investigated. Silicon was taken as the heat sink material and water as the working fluid was pumped into the microchannel. The fluid was heated through the bottom surface which was held at a uniform heat flux of $90 \mathrm{~W} / \mathrm{cm}^{2}$. The inlet velocity ranged from $29.07 \mathrm{~m} / \mathrm{s}$ to $81.39 \mathrm{~m} / \mathrm{s}$ with the corresponding Reynolds number from 2500 to 7000 . One branch of microchannel was taken as the computational domain. Detailed geometrical dimensions of one branch of microchannel are given in Table 1. A section view in a $x-y$ plane at $z=0.36 \mathrm{~mm}$ of each microchannel is shown in Figure 2.

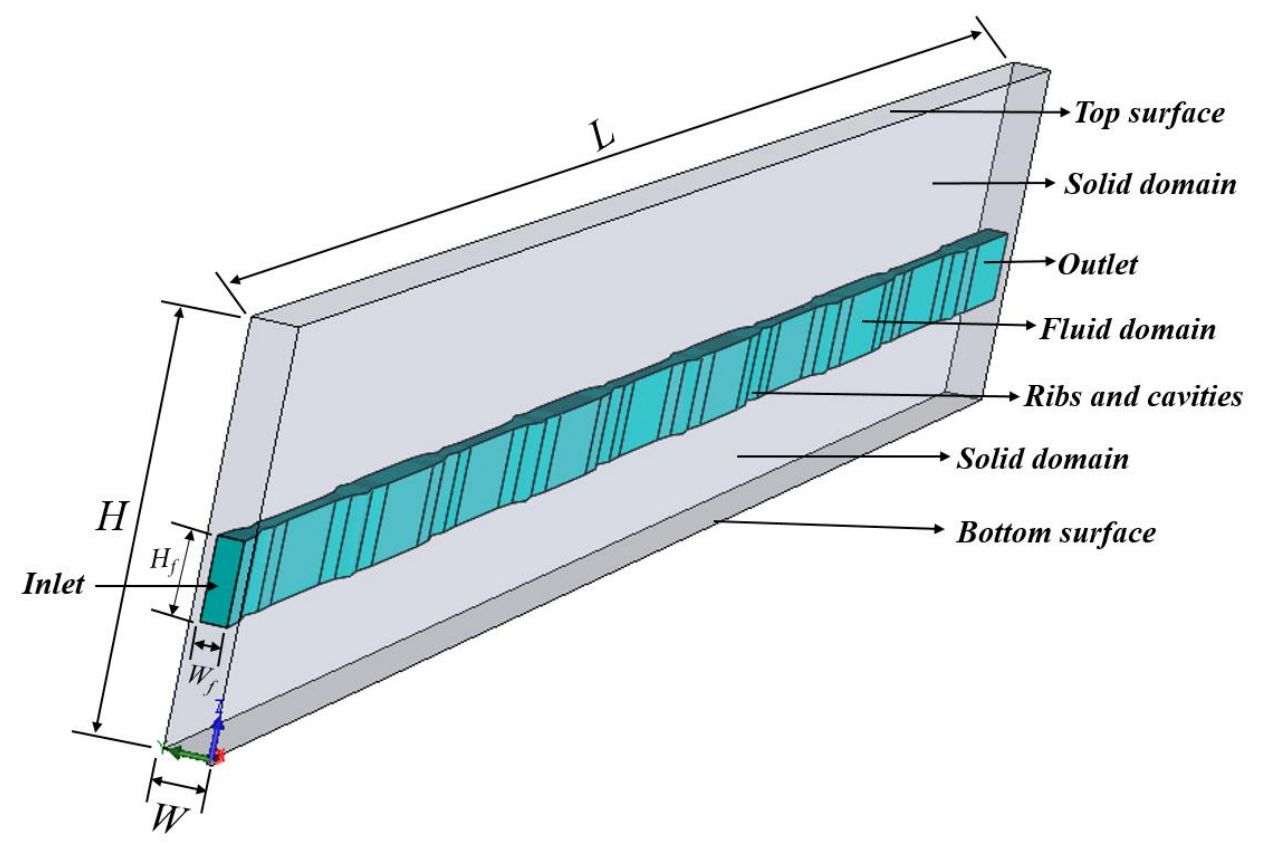

Figure 1. Computational domain (convergent-divergent microchannel with ribs and cavities).

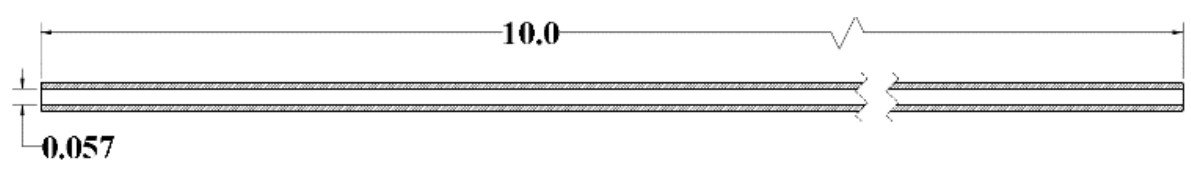

(a)

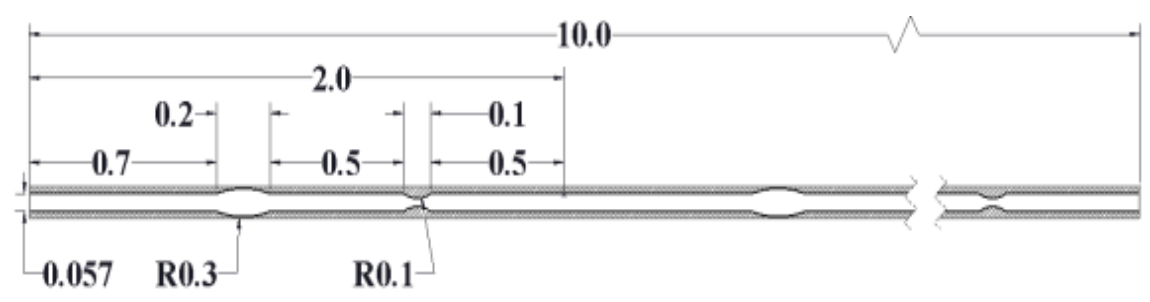

(b) 


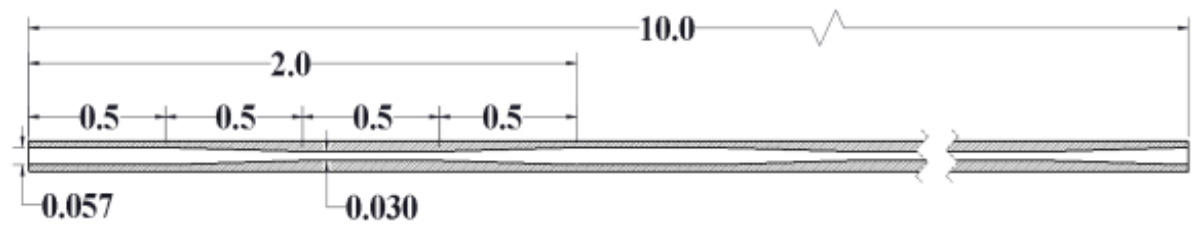

(c)

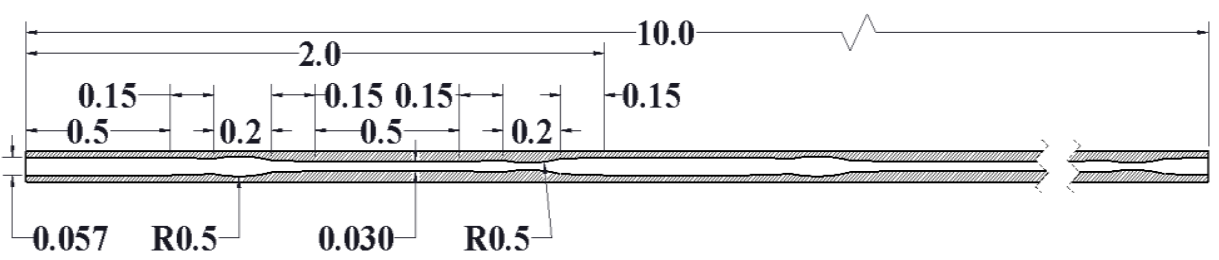

(d)

Figure 2. The cross-section of unit cells of different geometries: (a) rectangular, (b) rectangular with ribs and cavities, (c) convergent-divergent and (d) convergent-divergent with ribs and cavities.

\section{Governing Equations}

A single-phase, turbulent incompressible flow was considered in a microchannel. The effects of gravity and radiative heat transfer were assumed to be negligible. The associated conservation equations may be expressed as

Continuity:

$$
\frac{\partial}{\partial x_{i}}\left(\rho_{f} u_{i}\right)=0
$$

Momentum:

$$
\frac{\partial}{\partial x_{i}}\left(\rho_{f} u_{i} u_{j}\right)=-\frac{\partial p}{\partial x_{j}}+\frac{\partial}{\partial x_{i}}\left[\mu_{f}\left(\frac{\partial u_{j}}{\partial x_{i}}+\frac{\partial u_{i}}{\partial x_{j}}\right)\right]
$$

Energy:

$$
\frac{\partial\left(\rho_{f} u_{i} c_{p f} T\right)}{\partial x_{i}}=\frac{\partial}{\partial x_{i}}\left(k_{f} \frac{\partial T}{\partial x_{i}}\right)
$$

Turbulent kinetic energy equation (SST $k$ - $\omega$ turbulence model):

$$
\frac{\partial}{\partial x_{i}}\left(\rho_{f} k u_{i}\right)=\frac{\partial}{\partial x_{i}}\left[\left(\mu_{f}+\frac{\mu_{t}}{\sigma_{k}}\right) \frac{\partial k}{\partial x_{i}}\right]+G_{k}-\rho \varepsilon
$$

Conservation of turbulent dissipation rate (SST $k$ - $\omega$ turbulence model):

$$
\frac{\partial}{\partial x_{i}}\left(\rho_{f} \varepsilon u_{i}\right)=\frac{\partial}{\partial x_{i}}\left[\left(\mu_{f}+\frac{\mu_{t}}{\sigma_{\varepsilon}}\right) \frac{\partial \varepsilon}{\partial x_{i}}\right]+\frac{\varepsilon}{k} c_{1} G_{k}-c_{2} \rho \varepsilon
$$

where $k$ denotes the turbulent kinetic energy, $\varepsilon$ the turbulent dissipation rate, $G_{k}$ the generation of turbulent kinetic energy and $\mu_{t}$ the turbulent viscosity, respectively.

$$
\begin{gathered}
G_{k}=-\rho \overline{u_{\imath} u_{\jmath}} \frac{\partial u_{j}}{\partial x_{i}} \\
\mu_{t}=\frac{\rho C_{\mu} k^{2}}{\varepsilon}
\end{gathered}
$$


where, the model constants $C_{\mu}=0.09, C_{1}=1.44, C_{2}=1.92, \sigma_{k}=1.0$ and $\sigma_{\varepsilon}=1.3$.

The energy equation for solid may be written as:

$$
\frac{\partial}{\partial x_{i}}\left(k_{s} \frac{\partial T}{\partial x_{i}}\right)=0
$$

where $\rho$ denotes the density, $p$ the static pressure, $T$ the static temperature, $k$ the thermal conductivity of solid, $\mu$ the dynamic viscosity and $c_{p}$ the specific heat capacity.

\section{Boundary Conditions}

A constant heat flux of $90 \mathrm{~W} / \mathrm{cm}^{2}$ was provided at the bottom surface of the microchannel. A uniform fluid was pumped at the inlet with a constant inlet temperature of $293 \mathrm{~K}$. Silicon was taken as the material of the heat sink with a temperature dependent thermal conductivity as shown in Table 2 and thermo-physical properties of water are given in Table 3.

Table 2. Thermal conductivity of silicon substrate.

\begin{tabular}{cccccc}
\hline Temperature $(K)$ & 200 & 250 & 300 & 350 & 400 \\
\hline $\begin{array}{c}\text { Thermal } \\
\text { Conductivity }(W / m . K)\end{array}$ & 264 & 191 & 148 & 119 & 98.9 \\
\hline
\end{tabular}

Table 3. Thermo-physical properties of water.

\begin{tabular}{ccccc}
\hline $\mathbf{T}(\boldsymbol{K})$ & $\boldsymbol{\rho}\left(\boldsymbol{k g} / \mathbf{m}^{\mathbf{3}}\right)$ & $\mathbf{C}_{\mathbf{p}}(\boldsymbol{J} / \mathbf{k g} . \mathbf{K})$ & $\mathbf{K}(\boldsymbol{W} / \mathbf{m} . \mathbf{K})$ & $\begin{array}{c}\boldsymbol{\mu} \\
(\boldsymbol{P a} . \boldsymbol{s})\end{array}$ \\
\hline 293 & 998.1 & 4183 & 0.599 & 0.001004 \\
303 & 995.7 & 4174 & 0.618 & 0.0008015 \\
313 & 992.2 & 4174 & 0.635 & 0.0006533 \\
323 & 988.1 & 4174 & 0.648 & 0.0005494 \\
\hline
\end{tabular}

In the present study, the governing equations for three-dimensional flow with the two equations SST $k$ - $\omega$ turbulence model were used to determine velocity, pressure and temperature fields. The following boundary conditions were used to solve the governing equations.

\section{Velocity inlet boundary:}

A uniform inlet velocity with a constant temperature of $293 \mathrm{~K}$ was pumped in the microchannel. Table 4 presents the inlet velocity ranged from $29.07 \mathrm{~m} / \mathrm{s}$ to $81.39 \mathrm{~m} / \mathrm{s}$ with the corresponding Reynolds number from 2500 to 7000 .

$$
x=0: u_{f}=u_{i n}, T_{f}=T_{i n}
$$

Table 4. Inlet fluid velocity considered in the present investigation.

\begin{tabular}{ccccccccc}
\hline Sr. No. & 1. & 2. & 3. & 4. & 5. & 6. & 7. & 8. \\
\hline Inlet Velocity $(\mathrm{m} / \mathrm{s})$ & 29.07 & 32.00 & 34.88 & 40.70 & 46.51 & 58.14 & 69.77 & 81.39 \\
\hline
\end{tabular}

Pressure outlet boundary:

An atmospheric pressure was chosen as the outlet pressure of the microchannel

$$
x=10 \mathrm{~mm}, p_{f}=p_{\text {out }}
$$

where $p_{\text {out }}=0$ (gauge pressure).

For inner wall/fluid contact surface:

$$
\begin{gathered}
u=v=w=0 ; T_{s}=T_{f} \\
-k_{s}\left[\frac{\partial T_{s}}{\partial n}\right]_{w}=-k_{f}\left[\frac{\partial T_{f}}{\partial n}\right]_{w}
\end{gathered}
$$


where $n$ denotes the local coordinate normal to the wall.

Constant heat flux boundary:

A constant heat flux $q=90 \mathrm{~W} / \mathrm{cm}^{2}$ was applied on the base of the microchannel

$$
z=0, k_{s} \frac{\partial T_{s}}{\partial z}=q
$$

Left and right side wall condition:

Adiabatic boundary condition was used for the two sides of the computational domain

$$
\begin{gathered}
y=0, \frac{\partial T_{s}}{\partial y}=0 \\
y=0.10 \mathrm{~mm}, \frac{\partial T_{s}}{\partial y}=0
\end{gathered}
$$

Top surface:

Top surfaces were considered as adiabatic

$$
-k_{f} \frac{\partial T_{f}}{\partial z}=0 \text { or }-k_{s} \frac{\partial T_{s}}{\partial z}=0
$$

where $u_{\text {in }}$ denotes the inlet fluid velocity. The subscripts $f$ and $s$ refer to fluid and solid, respectively.

\section{Solution Method and Code Validation}

ANSYS Fluent 15 was used as a CFD solver to determine heat transfer and flow fields. The SIMPLE algorithm was adopted to deal with linkage between pressure and velocity. The scaled residues for continuity, momentum, energy, turbulent kinetic energy and dissipation were less than $1 \times 10^{-6}, 1 \times 10^{-6}, 1 \times 10^{-9}, 1 \times 10^{-9}$ and $1 \times 10^{-9}$, respectively, to ensure convergence. A grid sensitivity study was performed using different grid sizes for all geometries for $R e=2500$. The deviations in thermal resistance was $6 \%, 0.3 \%$ and $0.2 \%$, respectively, for 1.3 million, 2.0 million, 2.5 million and 3.3 million cells, respectively as shown in Table 5. Therefore, the third grid system with 2.5 million cells was chosen for further simulations as shown in Figure 3.

The code validation was carried out by comparing the thermal resistance using $k-\varepsilon$ and $k$ - $\omega$ turbulence models with the results obtained by Xie et al. [5], who used a classical correlation. They analysed a microchannel heat sink as a twodimensional flow through a narrow rectangular channel with a constant heat flux boundary condition at the base of the heat sink considering the capacity resistance and the conductive resistance. They performed comparisons between $3 \mathrm{D}$ numerical simulations using the $k-\varepsilon$ turbulence model and the conventional correlation as mentioned above and showed the effect of the inlet velocity on the thermal resistance. The corresponding Reynolds number was calculated based on the hydraulic diameter of the microchannel heat sink, which comes out ranging from 2500 to 8000 . In the present study, the thermal resistance was calculated using $k-\varepsilon$ and $k$ - $\omega$ turbulence models for $R e$ ranging 2500 - 8000 and compared with the results obtained by the above-mentioned conventional correlation. The results obtained by the $k$ - $\omega$ turbulence model were closer to the results by the conventional correlation with a deviation of approximately 12\% (Figure 4). A possible reason for this deviation is the presence of transition flow region in the microchannel while the conventional correlation is valid for a fully turbulent region. In addition, considering the limitations of the RANS approach [27] the present deviation is quite reasonable. Further a 3D RANS simulation is useful because it can account for complex flow resulting from a complicated geometry due to a convergent-divergent cross-section with ribs and cavities and thus provide a good physical understanding of heat transfer and fluid flow processes. Therefore this result is used to select the $k-\omega$ model turbulence model in the present study.

Table 5. Details of mesh for grid independence study.

\begin{tabular}{lccc}
\hline Mesh & $\begin{array}{c}\text { Mesh } \\
\text { size (million) }\end{array}$ & $\begin{array}{c}\text { Thermal resistance, } \\
\mathbf{R}\left(\mathbf{K . c m}^{2} / \mathbf{W}\right)\end{array}$ & $\begin{array}{c}\text { Deviation in } \\
\mathbf{R}\end{array}$ \\
\hline Mesh I & 1.3 & 0.0395 & --- \\
Mesh II & 2.0 & 0.0396 & $6 \%$ \\
Mesh III & 2.5 & 0.03949 & $0.3 \%$ \\
Mesh IV & 3.3 & 0.03958 & $0.2 \%$ \\
\hline
\end{tabular}




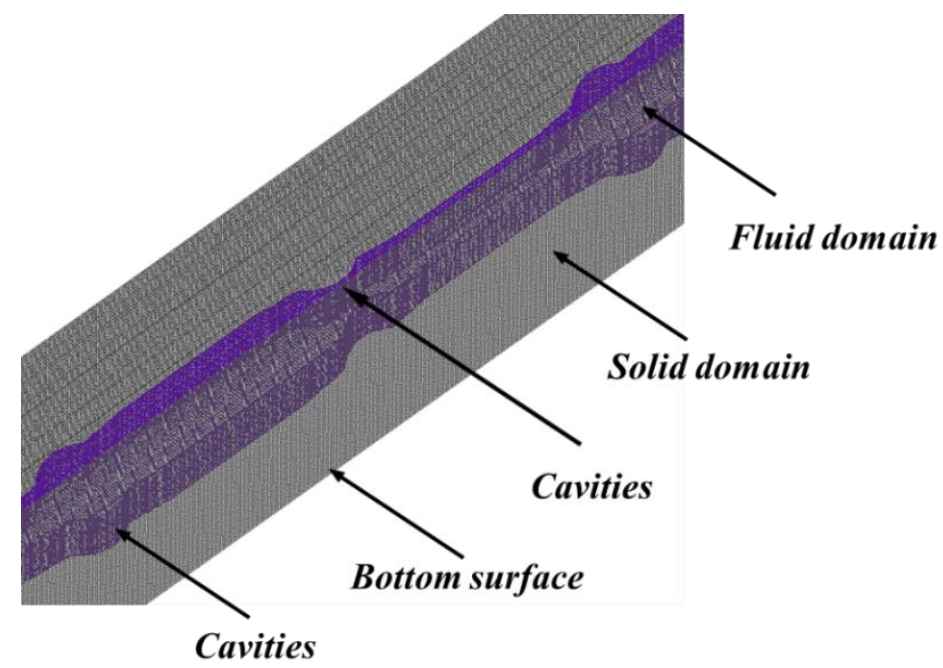

Figure 3. Computational grid for convergent divergent microchannel with ribs and cavities.

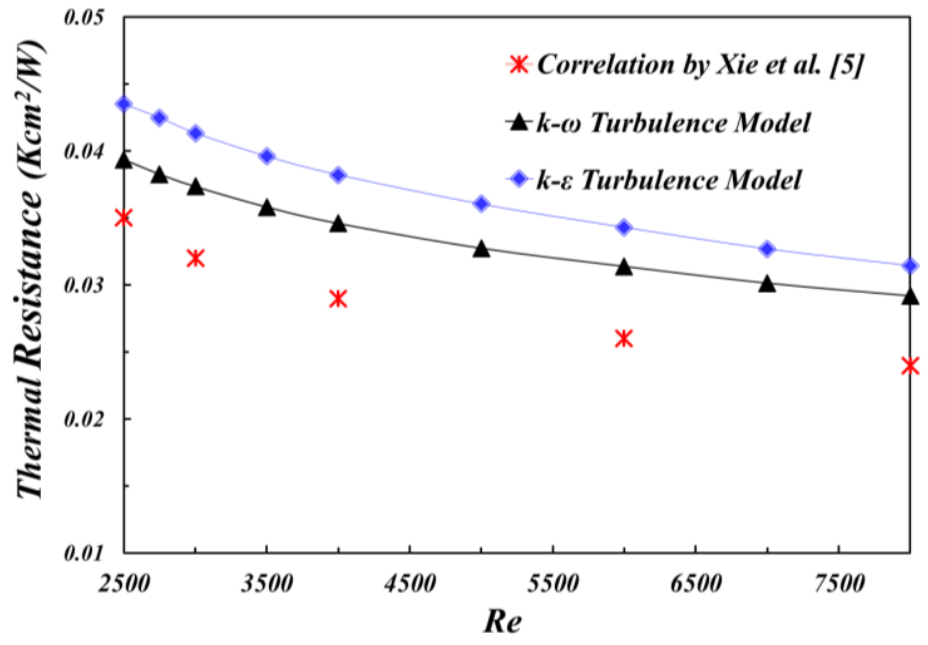

Figure 4. Comparison of present results with the reported correlation.

\section{Parameters Considered}

The Reynolds number at the inlet is defined as

$$
R e=\frac{\rho_{f} u_{i n} D_{h}}{\mu_{f}}
$$

where $D_{h}$ denotes the hydraulic diameter of the channel and $u_{\text {in }}$ the inlet fluid velocity.

The average fanning friction factor may be expressed as

$$
\bar{f}=\frac{\Delta p D_{h}}{2 \rho_{f} L u_{i n}^{2}}
$$

The average Nusselt number $(\overline{N u})$ was calculated from the average heat transfer coefficient $(\bar{h})$ and expressed as

$$
\begin{gathered}
R e=\frac{\rho_{f} u_{i n} D_{h}}{\mu_{f}} \\
\overline{N u}=\frac{\bar{h} D_{h}}{k_{f}}
\end{gathered}
$$


where, $q, n, A_{b}, A_{\text {cont }}, \overline{T_{w}}$ and $\overline{T_{f}}$ denote the heat flux, the number of microchannels, the bottom area, the solid-fluid contact area, the area averaged bottom surface temperature and the bulk fluid temperature, respectively.

Thermal resistance and pumping power are calculated by the expressions:

$$
R=\frac{T_{\max }-T_{i n}}{q}
$$

where $T_{\max }$ and $T_{\text {in }}$ are the substrate maximum and inlet fluid temperatures, respectively.

$$
R=\frac{T_{\max }-T_{i n}}{q}
$$

where $A_{c}$ denotes the inlet cross-sectional area per channel.

\section{RESULTS AND DISCUSSION}

The numerical results for each case including the average Nusselt number and thermal resistance are presented in this section. Thermal resistance has been taken as a performance evaluation criterion and it has been compared for various configurations for different values of $R e$ ranging from 2500 to 7000 .

\section{Flow Pattern}

In a rectangular microchannel, a thick boundary-layer forms due to parallel streamlines and it deteriorates its thermal performance. When ribs and cavities are incorporated in the flow domain, velocity decreases in the cavities and a full heat exchange occurs between water and heated wall. If retention of fluid in cavities is long, heat transfer decreases. It can be seen from Figure 5 that the presence of ribs and cavities changes flow field as compared to the rectangular microchannel in which streamlines are parallel. However, incorporation of ribs between the cavities increases the velocity and there is a strong mixing of hot and cold fluids. The maximum velocity occurs at the centre in the rectangular channel while in the case of rectangular channel with ribs and cavities, minimum velocity occurs at the cavity location. However, the maximum velocity occurs when flow passes through ribs. As shown in Figure 5, a periodic interruption of boundary-layers and local fluid mixing was observed near cavities and ribs. In the CD shaped microchannel, flow is accelerated in the convergent segment and attains the maximum velocity followed by a constant velocity in the uniform cross section zone with finally getting decelerated in the diverging segment. When ribs and cavities are used with the convergent-divergent shaped microchannel, fluid flows to cavity at the entrance of the contraction region, causing mixing of fluid and then fluid is again accelerated when it passes over the ribs.

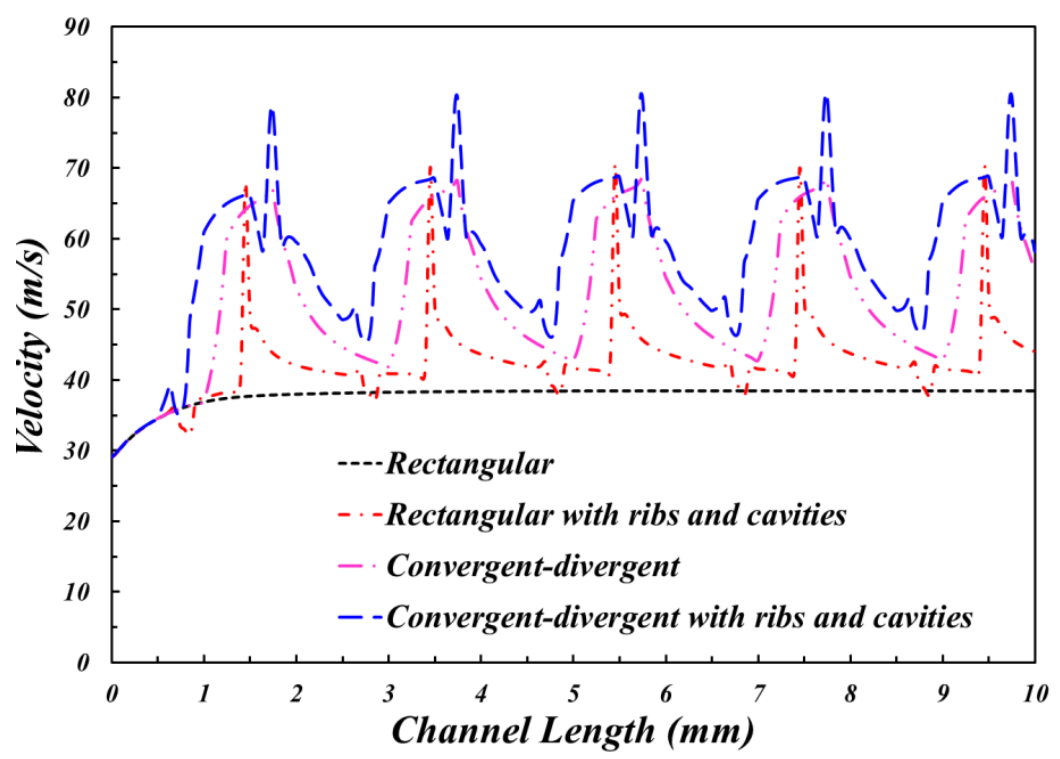

Figure 5. Velocity in $z-x$ plane in the middle of fluid region along the channel length for $R e=2500$.

Figure 6 shows the velocity and temperature distributions for microchannels in a $x-y$ plane located at the centre of the channel height $(z=0.36 \mathrm{~mm})$ at $R e=2500$. As shown in Figure 6(a), the streamlines are parallel to fluid flow direction and the peak velocity occurs at the channel centre. Due to thickening of thermal boundary-layer, heat transfer is small from the solid domain to the fluid domain which can be observed from the temperature contours. When ribs and cavities are incorporated in a rectangular microchannel, the peak velocity occurs while passing through the ribs and 
minimum velocity occurs in the cavities. This is due to a sudden expansion and contraction of flow area. Such change in velocity creates a strong mixing of cold and hot fluids leading to an enhancement in heat transfer from the solid domain to the fluid domain. It is also observed from Figure 6(b) that the temperature of the solid domain is more than that of the rectangular channel. In the convergent - divergent shaped microchannel, the maximum velocity occurs after the converging section and flow is retarded in the diverging section as shown in Figure 6(c). In the CD-RC microchannel, cavities in the converging segment and ribs in the divergent segment make periodic interruption of velocity and thermal boundary-layers leading to a developing flow in the microchannel as shown in Figure 6(d). It improves the heat transfer in terms of an increased average Nusselt number and uniform temperature distribution in the substrate material.

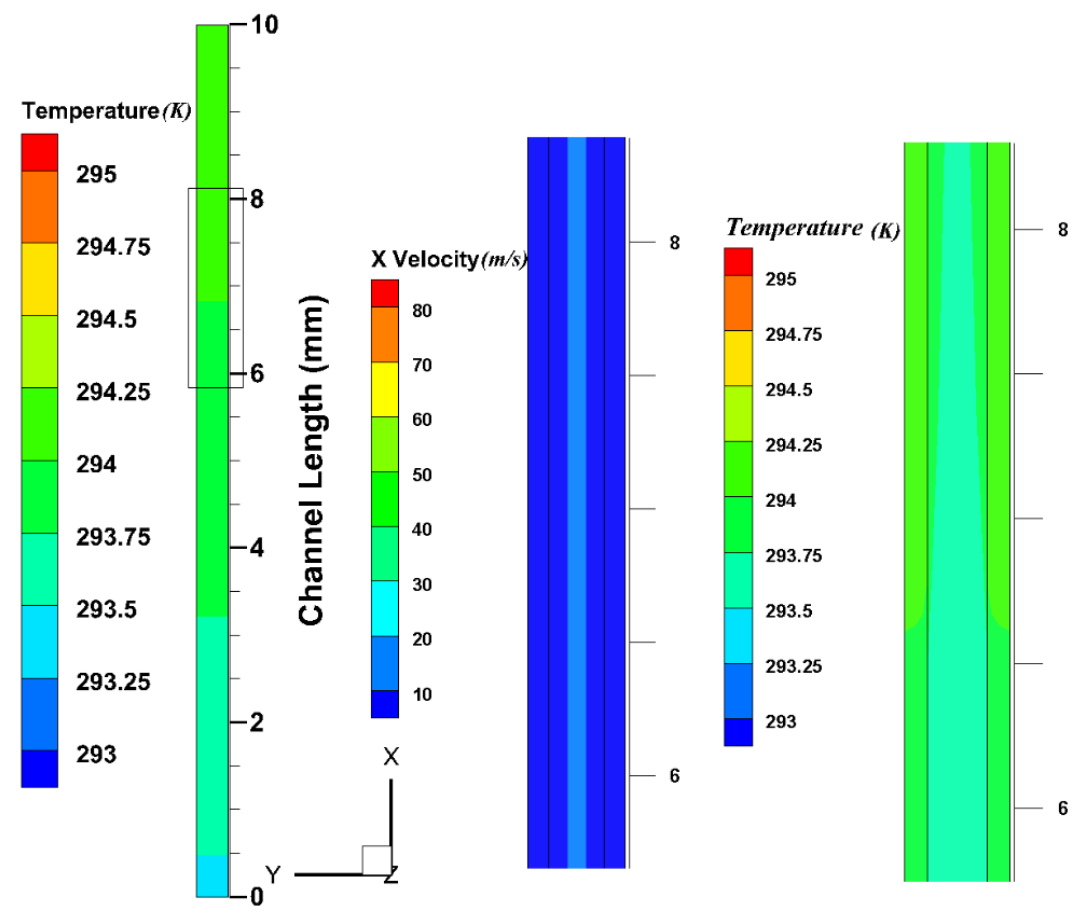

(a)

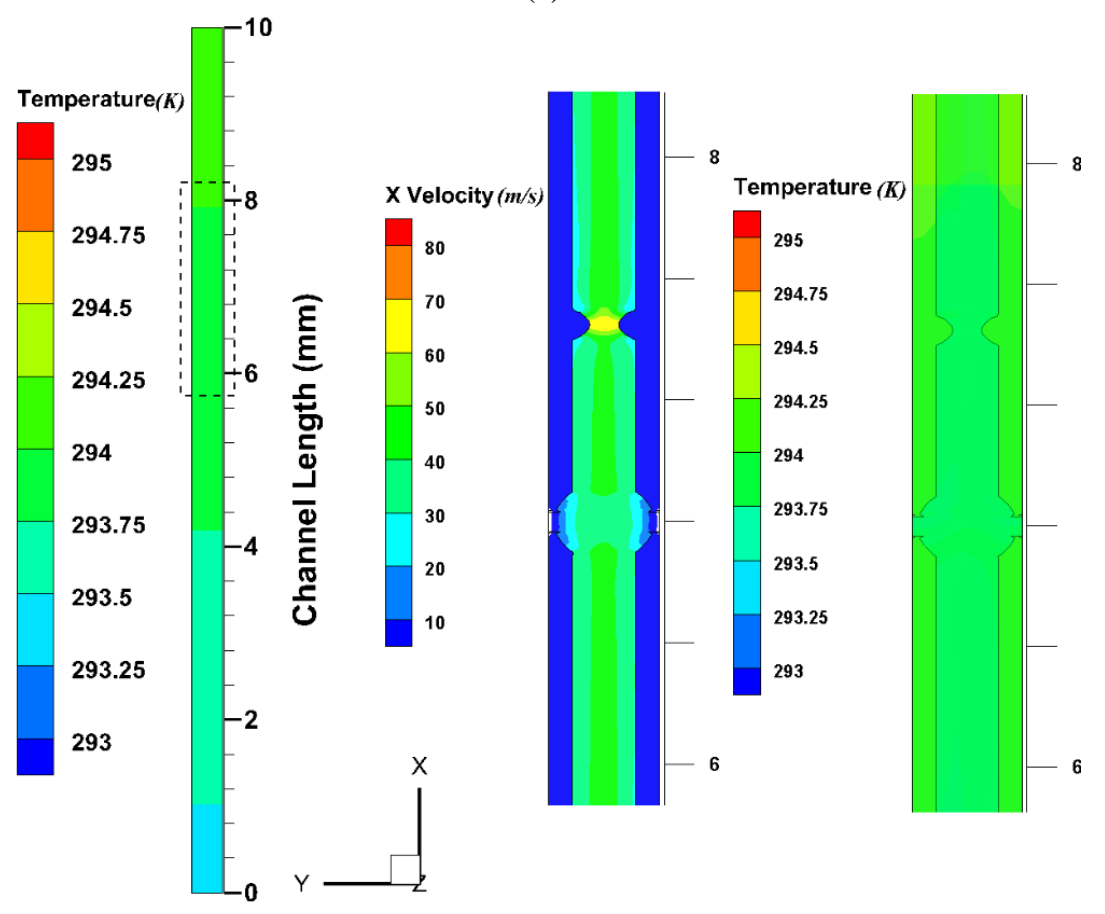

(b) 


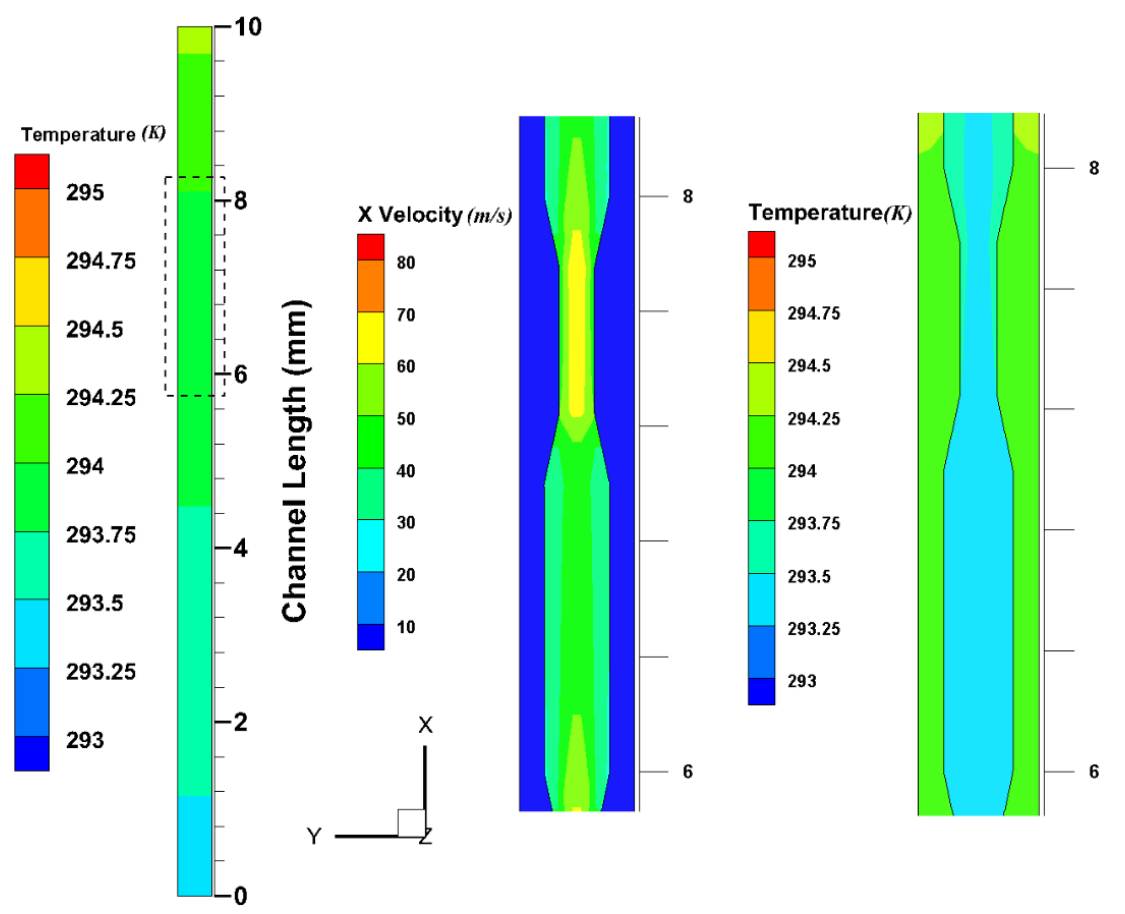

(c)

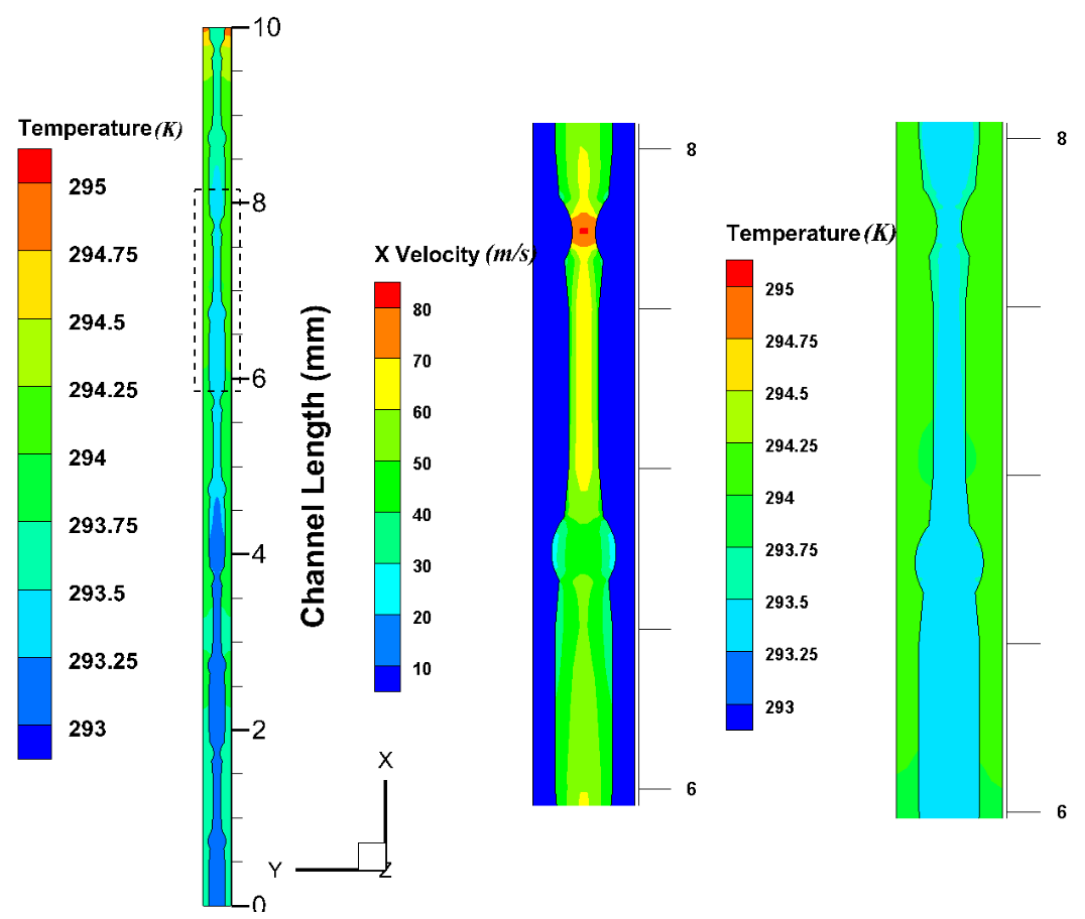

(d)

Figure 6. Temperature and velocity distributions along the channel length at $R e=2500$ at $z=0.36$ mm: (a) rectangular, (b) rectangular with ribs and cavities, (c) convergent-divergent and (d) convergent-divergent with ribs and cavities.

\section{Pressure Drop and Friction Factor}

When fluid flows in a rectangular channel, there is a pressure drop along the flow to overcome mainly frictional losses. In the case of a convergent-divergent shaped microchannel the pressure drop takes place due to fluid friction and flow passage configuration. Furthermore ribs and cavities disrupt the flow causing blocking effect and recirculation, thereby resulting in a higher pressure drop. Variations in pressure drop along the flow direction at $R e=2500$ are presented in Figure 7(a). It is well known that for a smooth microchannel, the pressure decreases gradually along the channel length. In a CD microchannel flow is forced to flow in different cross-section segments while ribs and cavities disturb the core flow field periodically. It is clear from Figure 7(a) that the effect of convergent-divergent shape on pressure drop is more dominant than ribs and cavity. The pressure drop for the CD-RC microchannel is highest in all cases considered due to flow disruptions. The effects of flow rate on the pressure drop are shown in Figure 7(b). There 
is a linear pressure drop for all cases considered up to some value of $R e$ and thereafter it increases rapidly. The pressure drop increases with $R e$ significantly. The pumping pressure for the $\mathrm{CD}-\mathrm{RC}$ microchannel is the highest among all the cases considered.

The total frictional loss can be obtained by summing different losses occurring in a microchannel. The major loss is due to a change in the channel shape where a periodic expansion and contraction takes place. Other losses are due to recirculation in cavities and flow blockages between ribs. A variation in friction factor with flow rate is shown in Figure 8. It is observed that the frictional loss is the highest for the CD-RC microchannel among all the cases considered.

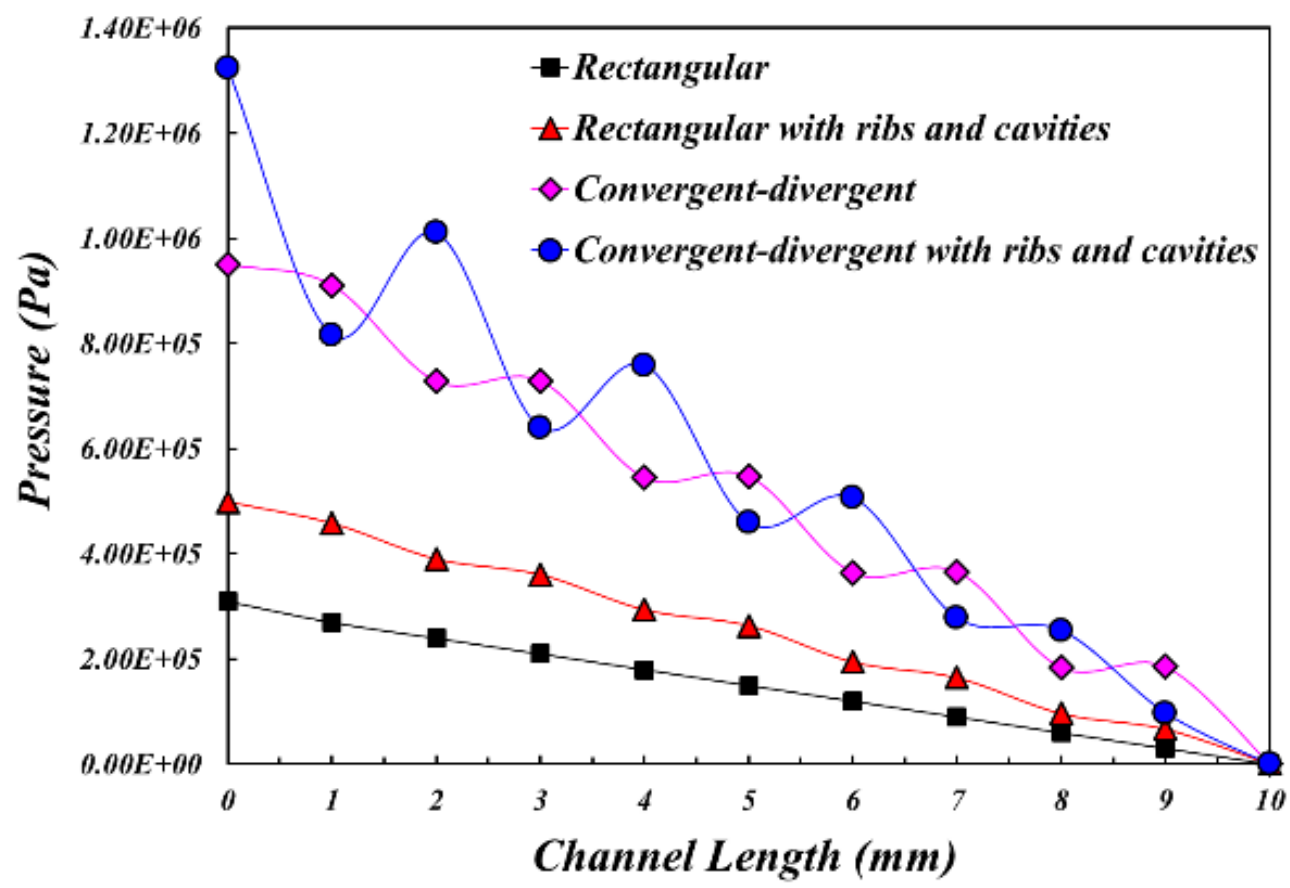

(a)

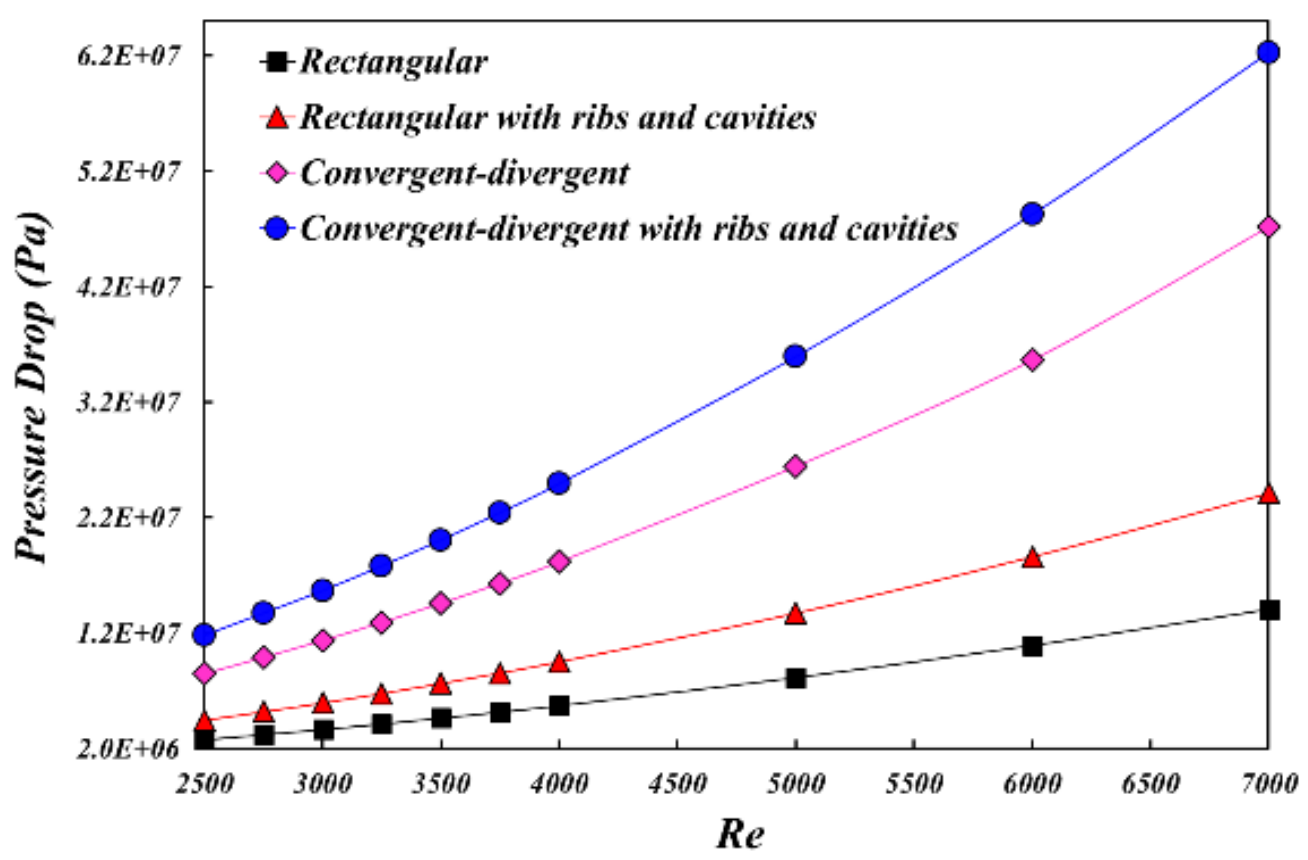

(b)

Figure 7. (a) Pressure drop along the channel length for $R e=2500$ and (b) pressure drop variation with $R e$. 


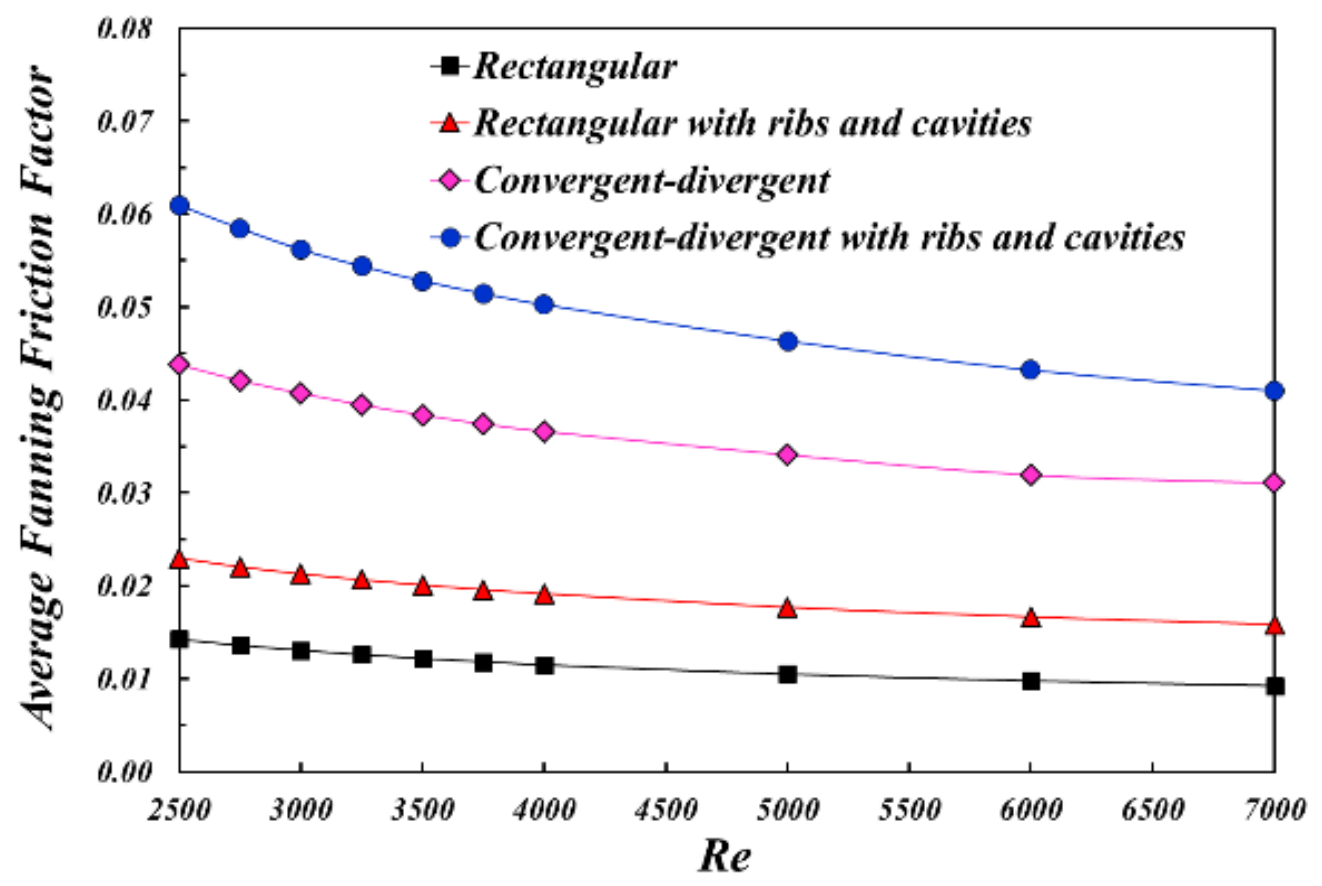

Figure 8. Variation in average friction factor with Reynolds number.

\section{Heat Transfer Characteristics}

In this section the effects of channel shape with ribs and cavities on heat transfer characteristics are presented. A change in the shape of a microchannel changes the flow direction so that it interrupts boundary-layer and hence a restart of boundary-layer takes place leading to an increase in heat transfer. Ribs and cavities are mainly used to enhance local heat transfer. This enhancement in heat transfer is not only due to an increase in the contact area but also due to a strong mixing of fluid. As fluid enters the cavity, velocity decreases and more time is available for heat transfer. At the same time, a longer retention of fluid into cavity also decreases heat transfer due to a poor mixing of fluid. Figure 6 shows the temperature distribution in an $x-y$ plane located at the middle of the fluid domain depth $(z=0.36 \mathrm{~mm})$ at $R e=2500$. It can be observed from Figure 6(a) that the temperature of the substrate for the rectangular channel is the highest among all the cases considered. This behavior is due to a poor heat transfer from the solid domain to the fluid domain. As the shape is changed using a convergent-divergent geometry, as shown in Figure 6(c), flow is accelerated in the convergent section and then decelerated in the divergent section leading to an interruption of boundary-layer and a strong mixing of cold and hot fluids. Such periodic change in velocity leads to lower the thermal resistance resulting in an enhancement of heat transfer. Figures 6(b) and 6(d) show the effect of ribs and cavities on rectangular and CD shaped microchannel. Interruption and redevelopment of boundary-layers takes place due to flow disruption by ribs leading to heat transfer enhancement.

Figure 9 shows the temperature distributions in $x-z$ plane of microchannels at the middle of the fluid domain ( $y=$ $0.050 \mathrm{~mm}$ ) for $R e=2500$. It can be observed from Figure 9(a) that the thermal boundary-layer thickens resulting in a poor heat transfer from the solid domain to fluid domain in the rectangular shape. The maximum temperature of fluid occurs in the centre of fluid and it is the highest among the all cases considered. However, Figure 9(d) shows the combined effects of CD shaped with ribs and cavities which lower the maximum temperature of the solid substrate due to a significant heat transfer between the solid and fluid domains. 


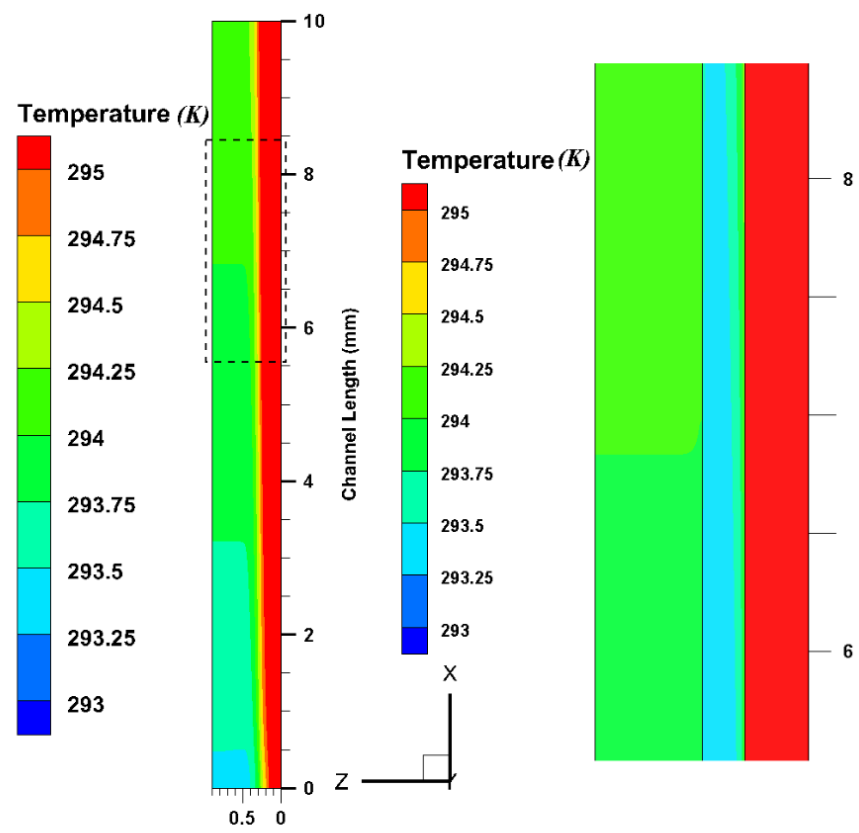

Channel Height (mm)

(a)

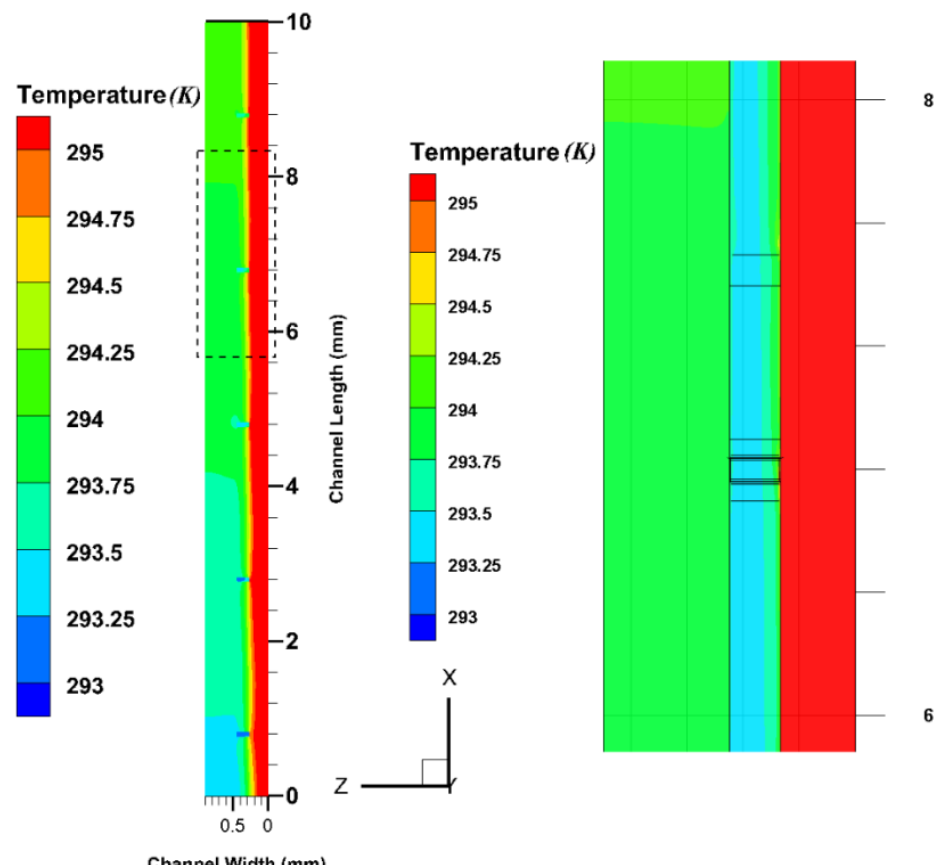

(b) 


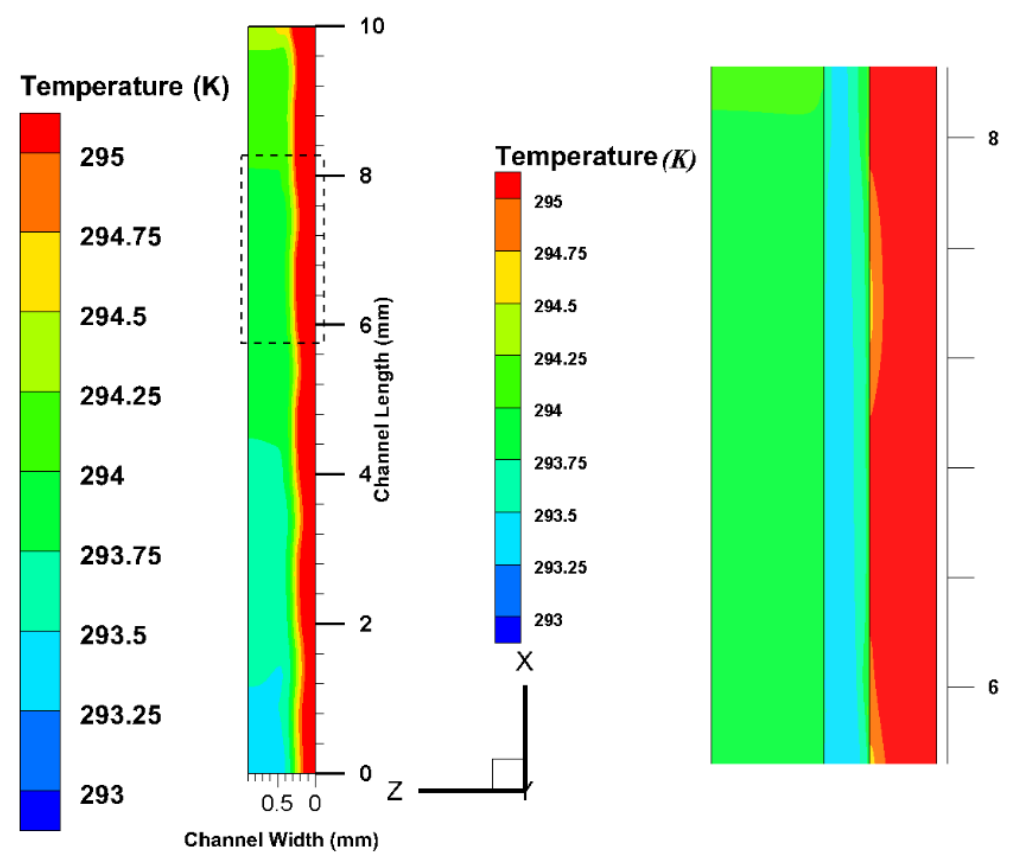

(c)

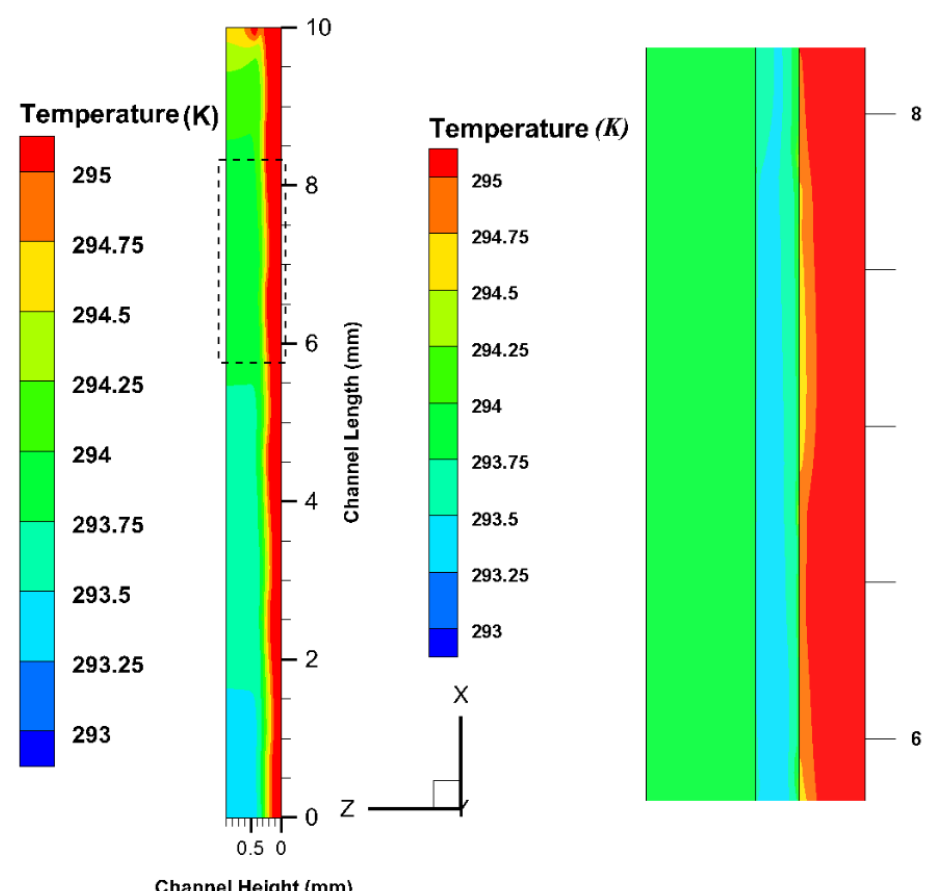

(d)

Figure 9. Temperature distributions along the channel length at $R e=2500$ at $z=0.36 \mathrm{~mm}$ (a) rectangular (b) rectangular with ribs and cavities (c) convergent-divergent and (d) convergent-divergent with ribs and cavities.

Due to a change in the channel shape with ribs and cavities, sudden expansion and contraction of flow area takes place which creates a strong mixing of cold and hot fluids leading to an enhancement in heat transfer from the solid domain to the fluid domain. In the CD-RC microchannel, the presence of cavities in the converging segment and ribs in the divergent segment result in hydraulic and thermal-boundary layer interruptions leading to an improvement in heat transfer in terms of an increased average Nusselt number. This increase in the averaged Nusselt number is due to a developing flow in the CD-RC microchannel. It is observed from Figure 10 that the average Nusselt number for the CD-RC microchannel is the highest among all the cases considered. An increase of $16 \%-40 \%$ in the average Nusselt number was observed in the $\mathrm{CD}-\mathrm{RC}$ microchannel compared to the rectangular shape for the range of $R e$ considered. 


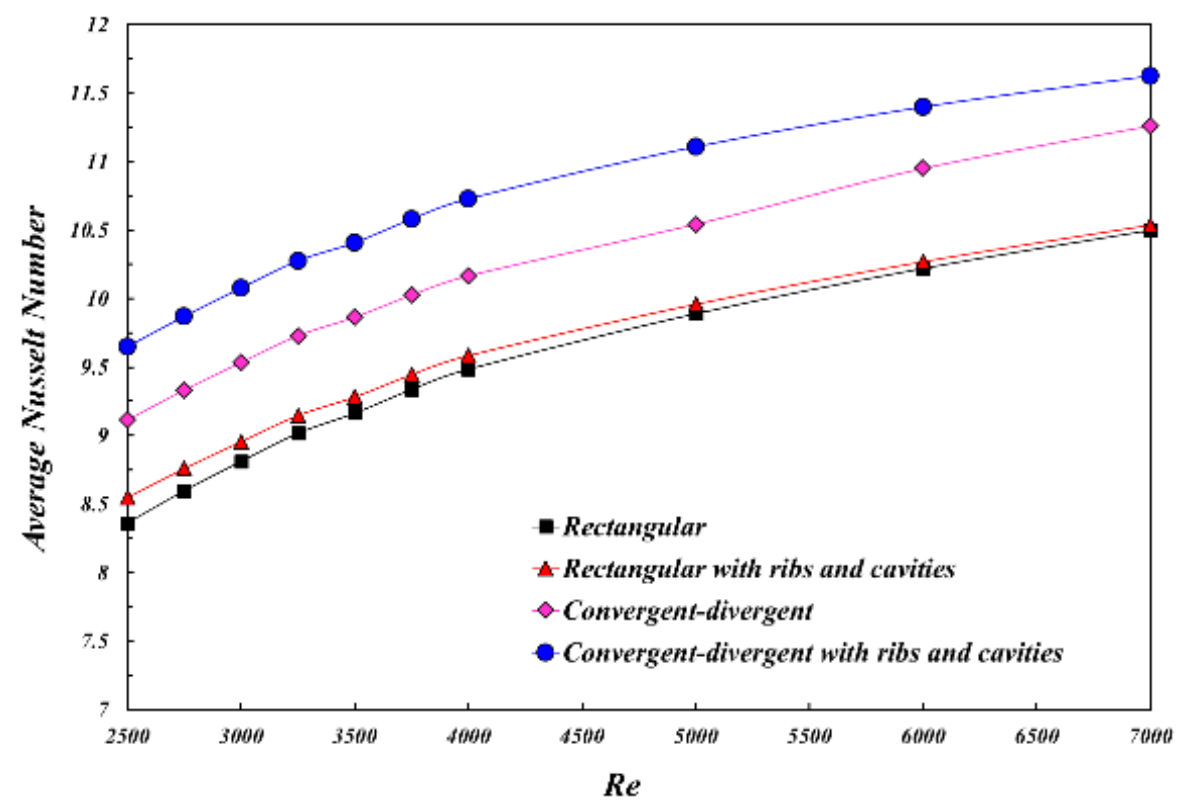

Figure 10. Variation in average Nusselt number with Reynolds number.

The substrate temperature is given the most attention in chip cooling as a chip is directly mounted on this surface. Figure 11(a) shows variations in the area-weighted bottom wall temperature along the channel length at $R e=2500$. It can be observed from Figure 11(a) that the bottom surface temperature rises linearly with $R e$ in the case of the rectangular channel, while the rectangular channel with ribs and cavities has a lower value and it periodically increases and decreases at the locations of ribs and cavities. In the CD microchannel, the substrate temperature lowers in the converging section and increases in the diverging section. At the same location the substrate temperature of the CD-RC channel is the minimum among the all cases considered due to an increase in temperature encountered in the CD shape. Figure 11(b) shows a variation of the area weighted bottom surface temperature with the flow rate. It can be seen that the average bottom surface temperature decreases with flow rate for all the cases considered. The rate of decrease of the average bottom surface temperature reduces with $R e$. A small temperature variation with the least substrate temperature was observed in the CD-RC microchannel.

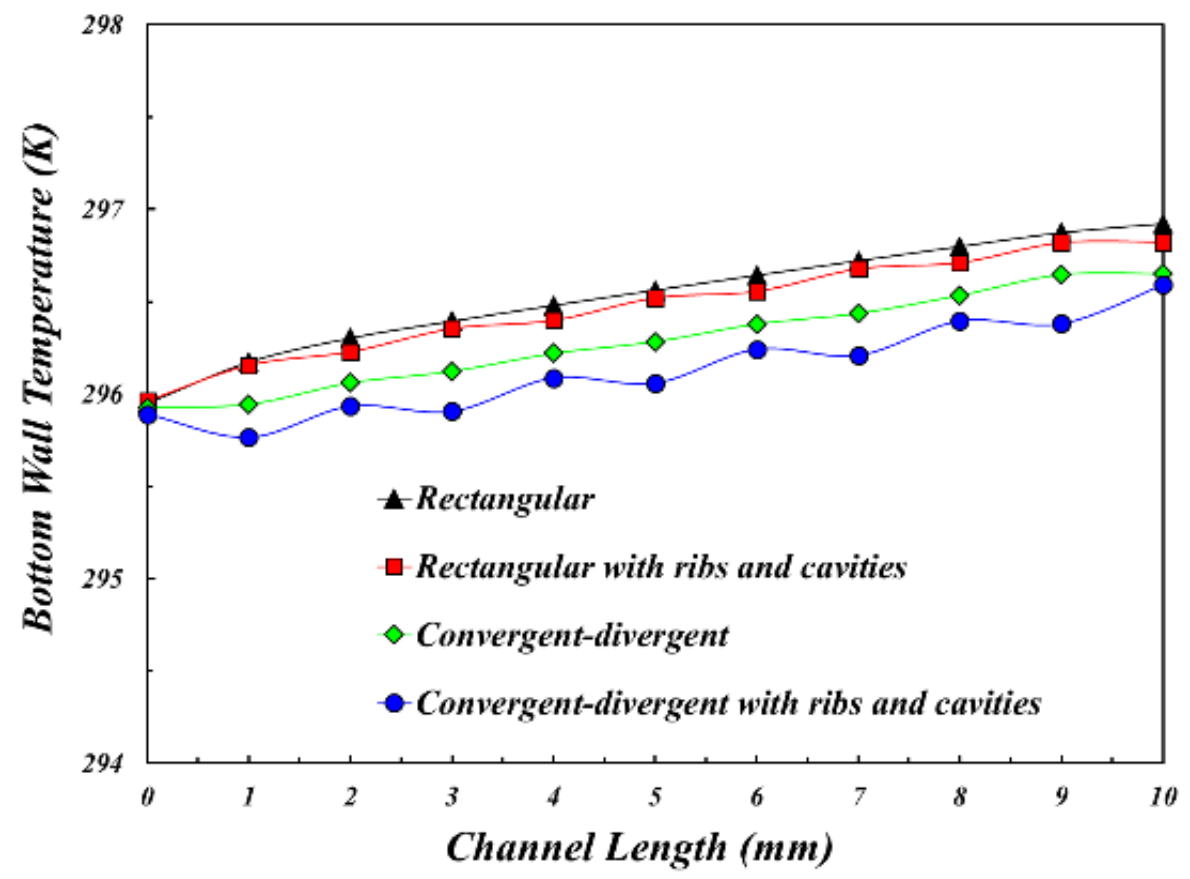

(a) 


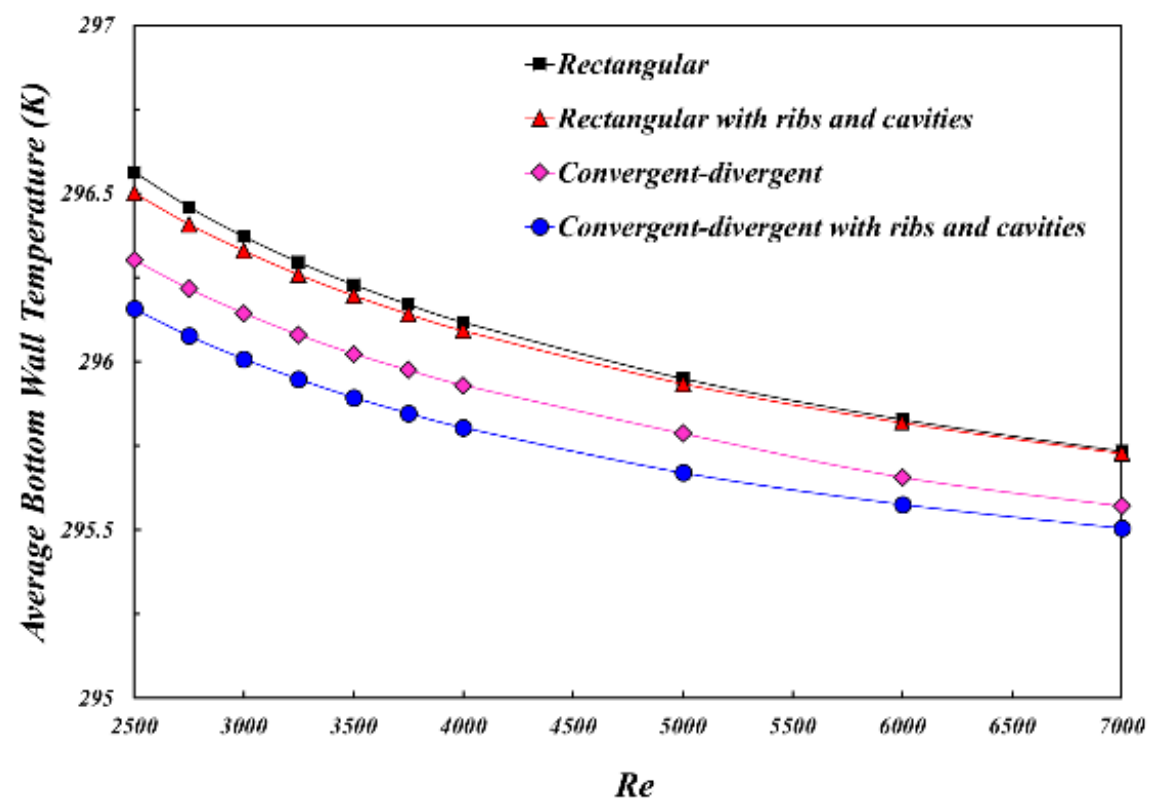

(b)

Figure 11. (a) Bottom wall temperature along the channel length for $R e=2500$ and (b) bottom wall temperature variation with $R e$.

\section{Overall Thermal Performance Evaluation}

Thermal resistance, which is the ratio of the temperature difference of the substrate and inlet temperature to heat flux, is a commonly used parameter for the performance evaluation in chip cooling. Figure 12 shows variations in thermal resistance with $R e$ in the range of $2500-7000$. It can be observed that with an increase in $R e$, the thermal resitance drops quickly for all the cases. This behaviour is due a decrease in the convective resitance with an increase in $R e$. The increase of heat transfer coefficient eventually increases the average Nusselt number with $R e$ leading to a decrease in the convective resistance. It is observed that for a given $R e$ the thermal resistance of the CD-RC microchannel is much lower than that of the rectangular microchannel. Further decrease in the thermal resistance is the highest for the CD shape of channel than for ribs and cavities only as shown in Figure 12. It can also be obseved from Figure 12 that a further increase of flow rate makes less contribution to a decrease in the overall thermal resistance and hence its effectiveness is gradually lost at higher flow rate.

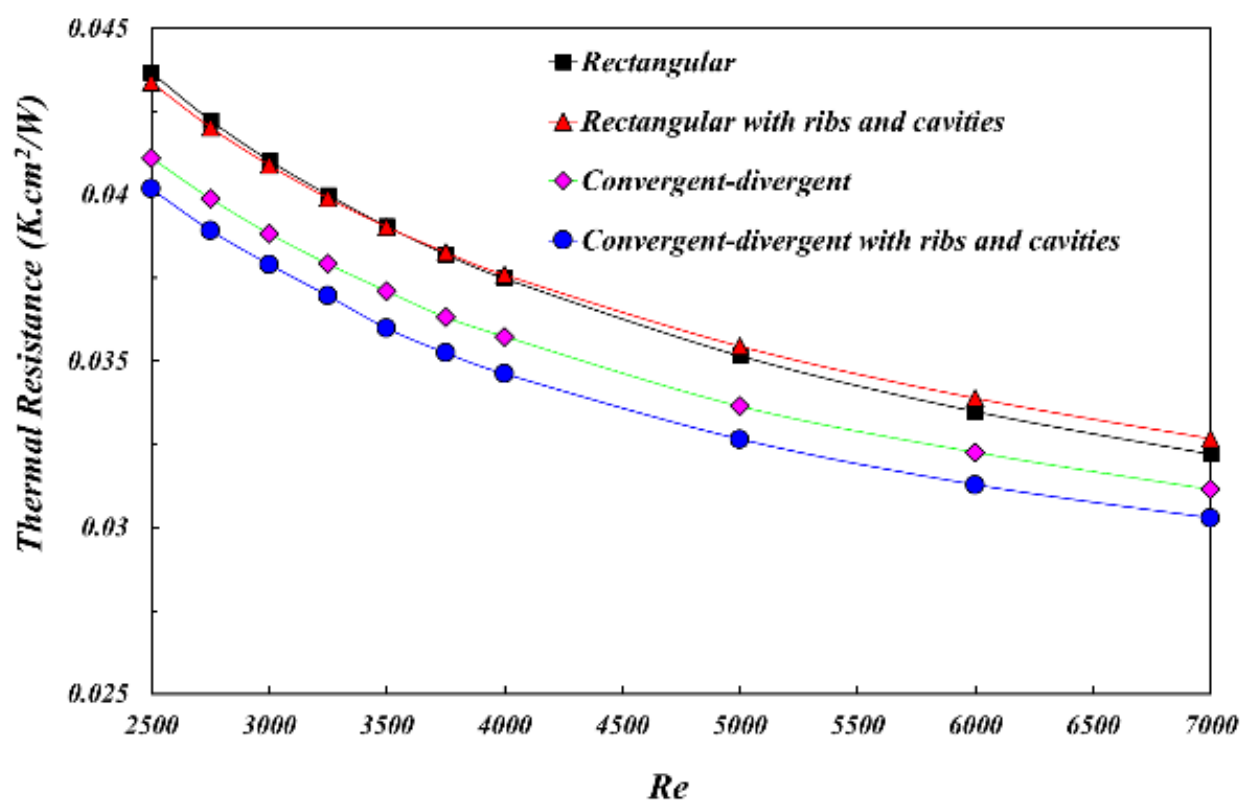

Figure 12. Variation in thermal resistance with Reynolds number. 


\section{CONCLUSIONS}

The individual effects of different shapes of microchannel, such as, $I, U$, serpentine, etc. and the use of pillars, baffles, prismatic ribs and their configurations, on thermal characteristics were analysed by many researchers to augment turbulent heat transfer. In the present paper, turbulent heat transfer characteristics are analysed in a Convergent - Divergent (CD) shaped microchannel with Ribs and Cavities (RC) for Re ranging from 2500 - 7000. Due to a change in the channel shape, sudden expansion and contraction of flow takes place which creates a strong mixing of cold and hot fluids leading to an enhancement in heat transfer from the solid domain to the fluid domain. In the CD-RC microchannel, the presence of cavities in the converging segment and ribs in the divergent segment results in interruptions of the hydraulic and thermal-boundary layers leading to an improvement in heat transfer in terms of an increased average Nusselt number. The investigation shows that the average Nusselt number increases from $16 \%$ to $40 \%$ with an increase in the flow rate considered. The combined effects of the CD shape with ribs and cavities produce an enhanced fluid mixing with periodic interruptions of boundary-layer leading to an improved thermal performance of the microchannel. It is also observed that the $\mathrm{CD}-\mathrm{RC}$ microchannel has the least overall thermal resistance and it decreases by $30 \%$ over the range of Re considered. Lower and smaller variations in the heated surface temperature are also observed which are essential for an electronic cooling. At the same time, the CD shaped microchannel requires more pumping power to remove the same amount of heat as compared to a rectangular microchannel and therefore a trade-off between overall thermal resistance and pumping power is observed. A parametric study dealing with effects of the substrate thickness along with the curvature of the convergent-divergent section on overall thermal resistance may be further performed to obtain an optimum overall thermal performance.

\section{REFERENCES}

[1] Tuckerman DB, Pease RFW. High-performance heat sinking for VLSI. IEEE: Electronic Device Letter. 1981; 12: 126-129.

[2] Qu W, Mudawar I. Analysis of three dimensional heat transfer in micro-channel heat sink. International Journal of Heat and Mass Transfer. 2004; 45: 3973-3985.

[3] Dewan A, Srivastava P. A review of heat transfer enhancement through flow disruption in a microchannel, Journal of Thermal Science. 2015; 24: 203-214.

[4] Kamal H, Dewan A. Analysis of interrupted rectangular microchannel heat sink with high aspect ratio, Journal of Applied Fluid Mechanics. 2017; 10: 117-126.

[5] Xie XL, Tao WQ, He YL. Numerical study of turbulent heat transfer and pressure drop characteristics in a water-cooled minichannel heat sink. ASME: Journal of Electronic Packaging. 2007; 129: 247-255.

[6] Srivastava P, Dewan A, Bajpai JK. Flow and heat transfer characteristics in convergent-divergent shaped microchannel with ribs and cavities. International Journal of Heat and Technology. 2017; 35: 863-873.

[7] Duryodhan VS, Singh A, Singh SG, Agrawal A. Convective heat transfer in diverging and converging microchannels, International Journal of Heat and Mass Transfer. 2015; 80: 424-438.

[8] Srivastava P, Dewan A. Effect of bifurcation on thermal characteristics of convergent-divergent shaped microchannel. ASME Journal of Thermal Science and Engineering Applications. 2018; 10: 041008.

[9] Hussein AM, Sharma KV, Bakar RA, Kadirgama K. Heat transfer enhancement with nanofluids - A Review. Journal of Mechanical Engineering and Sciences, 2013; 4: 452-461.

[10] Sangmesh B, Gopalakrishna K, Manjunath SH, Kathyayini N, Kadirgama K, Samykano M, Vijayakumar GC. Experimental investigation on HSFP using MWCNT based nanofluids for high power light emitting diodes. Journal of Mechanical Engineering and Sciences, 2018; 12(3): 3852-3865.

[11] Abidin SZ, Mohamad IS, Bani Hashim AY, Abdullah N, Hafiz MIM, Masripan NAB, Abdullah A. Investigation of thermal characteristics of CNF-based nanofluids for electronic cooling applications. Journal of Mechanical Engineering and Sciences, 2016; 10(3): 2336-2349.

[12] Menni Y, Azzi1 A, Chamkha A J. Optimal thermo aerodynamic performance of s-shaped baffled channels. Journal of Mechanical Engineering and Sciences, 2018; 12(3): 3888-3913.

[13] Liu D, Garimella SV. Investigation of liquid flow in micro channels. AIAA: Journal of Thermophysics and Heat Transfer. 2004; 18: 65-72.

[14] Wang BX, Peng XF. Experimental investigation on liquid forced convection heat transfer through microchannels. International Journal of Heat and Mass Transfer. 1994; 37: 73-82.

[15] Adams TM, Dowling MF, Abdel-Khalik SI, Jeter SM. Applicability of traditional turbulent single-phase forced convection correlations to non-circular microchannels. International Journal of Heat and Mass Transfer. 1999; 42: 4411-4415.

[16] Li H, Olsen MG. Micro-PIV measurements of turbulent flow in square microchannels with hydraulic diameters from 200 to $640 \mu \mathrm{m}$. International Journal of Fluid Flow. 2006; 27: 123-134.

[17] Oumer AN, Rao NT, Basrawi F, Ibrahim H. Numerical simulation on flow and heat transfer characteristics of supercritical fluids in mini-channels. Journal of Advances in Technology and Engineering Research. 2016; 2(3) :81-86.

[18] Rahman MM. Measurements of heat transfer in microchannel heat sink. International Communications in Heat and Mass Transfer. 2000; 27: 495-506. 
[19] Al-Neama AF, Kapur N, Summers J, Thompson HM. An experimental and numerical investigation of the use of liquid flow in serpentine microchannels for microelectronics cooling. Applied Thermal Engineering. 2017; 116: 709-723.

[20] Adib MAHM, Tuah NN, Hasni NHM, Osman K. Prediction of blood pressure in S shaped model of artery under normal blood pressure. Journal of Mechanical Engineering and Sciences. 2013; 4: 496-503.

[21] Cheng KX, Chong YS. Ooi K T. Thermal-hydraulic performance of a tapered microchannel. International Communications in Heat and Mass Transfer. 2018; 94: 63-60.

[22] Chan SM, Chong KH, Wong BT. The effect of $10 \mu \mathrm{m}$ microchannel on thermo-hydraulic performance for singlephase flow in semi-circular cross-section serpentine. Journal of Mechanical Engineering and Sciences. 2018; 12: 3724-3737.

[23] Wang Y, Houshm F, Elcock D, Peles Y. Convective heat transfer and mixing enhancement in a microchannel with a pillar. International Journal of Heat and Mass Transfer. 2013; 62: 553-561.

[24] Rezaei O, Akbari OA, Marzban A, Toghraie D, Pourfattah F, Mashayekhi R. The numerical investigation of heat transfer and pressure drop of turbulent flow in a triangular microchannel, Physica-E, Low Dimensional Systems Nanostructures. 2017; 93 : 179-189.

[25] Sharma N, Tariq A, Mishra M. Detailed heat transfer and fluid flow investigation in a rectangular duct with truncated prismatic ribs. Experimental Thermal and Fluid Science. 2018; 96: 383-396.

[26] Abdulrazzaq T, Togun H, AAriffin MK, Kazi SN, Adam NM, Masuri S. Numerical simulation on heat transfer enhancement in channel by triangular ribs. International Journal of Mechanical, Aerospace, Industrial and Mechatronics Engineering. 2013; 7: 605-609.

[27] Dewan A. Tackling Turbulent Flow in Engineering. 2011, Springer, Berlin. 